\title{
Community reorganization in the Gulf of Alaska following ocean climate regime shift
}

\author{
Paul J. Anderson ${ }^{1, *}$, John F. Piatt ${ }^{2}$ \\ ${ }^{1}$ National Marine Fisheries Service, Alaska Fisheries Science Center, 301 Research Court, Kodiak, Alaska 99615, USA \\ ${ }^{2}$ U.S. Geological Survey, Alaska Biological Research Center, 1011 E. Tudor Rd., Anchorage, Alaska 99503, USA
}

\begin{abstract}
A shift in ocean climate during the late 1970s triggered a reorganization of community structure in the Gulf of Alaska ecosystem, as evidenced in changing catch composition on long-term (1953 to 1997) small-mesh trawl surveys. Forage species such as pandalid shrimp and capelin declined because of recruitment failure and predation, and populations have not yet recovered. Total trawl catch biomass declined $>50 \%$ and remained low through the 1980 s. In contrast, recruitment of high trophiclevel groundfish improved during the 1980s, yielding a $>250 \%$ increase in catch biomass during the 1990s. This trophic reorganization apparently had negative effects on piscivorous sea birds and marine mammals.
\end{abstract}

KEY WORDS: Shrimp C Capelin · Forage fish Gulf of Alaska - Groundfish · Climate change

\section{INTRODUCTION}

The inshore ecosystem of the Gulf of Alaska (GOA) has undergone a shift from an epibenthic community dominated largely by crustaceans to one now dominated by several species of fishes (Anderson et al. 1997). These changes led to extreme disruption of local fishing economies and prompted concerns about how living resources in the GOA should be managed (Botsford et al. 1997, Orensanz et al. 1998). Before we can properly manage oceanic ecosystems, however, we need to know how marine climate induces changes in community structure over short and long time periods. Biological responses to climate change should not be considered ecological disasters or harmful to the marine ecosystem in general (Steele 1991). Adaptive management strategies that respond to ecosystem changes as they occur are needed for successful longterm management of fisheries (Botsford et al. 1997).

Ocean climate in the Gulf of Alaska cycles between warm and cold regimes on a multi-decadal time scale (Francis et al. 1998, McGowan et al. 1998). Two cycles are apparent in this century, with phase reversals oc-

•E-mail: paul.j.anderson@noaa.gov curring in 1925, 1947 and 1977 (Mantua et al, 1997). During the last reversal from a cold (1947 to 1976) to a warm regime (1977 to the present), the Aleutian Low pressure system shifted south and intensified, leading to stronger westerly winds and warmer surface waters in the GOA. Biological consequences included a marked improvement in groundfish recruitment (Hollowed \& Wooster 1992) and sharply increased Pacific salmon Oncorhynchus spp. catches in Alaska (Francis \& Hare 1994). In contrast, some forage fish populations collapsed (Anderson et al. 1997, Bechtol 1997) to the detriment of piscivorous sea bird and marine mammal populations (Piatt \& Anderson 1996, Merrick et al. 1997). Mechanisms by which a shift in ocean climate induced these biological changes are unclear and the magnitude of the biological response is unknown (Francis et al. 1998, McGowan et al. 1998). Here we show extensive reorganization of the GOA marine ecosystem following the 1977 climate regime shift and propose some mechanisms to explain the observed changes.

\section{METHODS AND MATERIALS}

Small-mesh trawl surveys for shrimp were conducted by the National Marine Fisheries Service (NMFS) and 
the Alaska Department of Fish and Game (ADF\&G) from 1953 to 1997. Sampling areas were designated by early exploratory surveys that had the purpose of locating commercial quantities of shrimp. Over $90 \%$ of survey tows were conducted in May to October. Early surveys had shown that shrimp concentrate in relatively deeper locations in the inshore bays and gullies of the GOA (Ronholt 1963). Consequently, most survey tows were restricted to depths greater than $55 \mathrm{~m}$. After 1971, survey strata were designed for all known major shrimp concentrations in the central and western GOA. Random tow sampling locations within each stratum were selected for each survey from 1972 to the present. Prior to 1972, trawls were conducted with a variety of small-mesh gear having different catch efficiencies. These data are used here to compare relative (\%) catch composition from 1953 to 1997. From 1972 onward, ADF\&G and NMFS standardized methods and used 'high-opening' trawls with $32 \mathrm{~mm}$ stretchedmesh throughout (Anderson 1991). Catch per unit effort (CPUE) was calculated as $\mathrm{kg}$ caught per $\mathrm{km}$ trawled. Between 1953 and 1997, 8996 trawls covering $17406 \mathrm{~km}$ were conducted (Fig. 1). Annual effort averaged 259 trawls $\mathrm{yr}^{-1}$ (range: 22 to 775 ). To examine trends in mean catch biomass we used only trawls ( $\mathrm{n}=$ 6812) conducted after 1971. Overall, mean and median CPUEs were similar $(\mathrm{r}=0.94)$, and we used mean catch data for all calculations and to illustrate biomass trends in all species except Pacific cod, where a few high catches confounded the apparent trend. To illustrate cod trends with a comparable scale, we used an index of CPUE derived from median values by regression.

Catches were compared to 4 available climate indices for the GOA study area: the North Pacific Pressure
Index (NPPI, an index of air pressure at sea level), sea surface temperatures (SST), GOA air temperatures, and GOA bottom water temperatures. The NPPI index was obtained from S. Hare, Univ. of Washington, Seattle, USA, and is the same as that reported in Mantua et al. (1997). Anomalies from November to March were normalized, and positive values of the NPPI correspond to years with a deepened Aleutian Low (Mantua et al. 1997). The NPPI provides an index of large-scale and low-frequency climate signals that are widespread and detectable in the North Pacific at interdecadal time scales. Changes in atmospheric pressure patterns in the North Pacific can create persistent blocking ridges that lead to decadal or longer shifts in pressure patterns and storm tracks (Wilson \& Overland 1986). An index of sea level pressure and its concomitant effect on horizontal and vertical mixing through wind stress is probably important in understanding recruitment variability of near-shore species with critical larval phases. Models of phytoplankton and zooplankton dynamics are sensitive to upper ocean mixed layer depths and temperatures (Polovina et al. 1995).

Coastal SST time series for British Columbia were obtained from the Institute of Ocean Sciences in Sidney, British Columbia, Canada. No other comparable SST data sets are available for the northern GOA. Normalized anomalies were calculated from a composite of 7 widespread coastal observing stations: Amphitrite Point, Race Rocks, Langara Island, Kains Island, McInnes Island, Entrance Island, and Pine Island. We used this index of near-shore SST in an attempt to integrate the wide variation that is typically seen in an area that has diverse topography like the GOA. This is similar to the index used by Mantua et al. (1997) in their analysis of North Pacific salmon production, but we did not include as many sites because of data gaps.

Coastal GOA air temperatures were obtained from the USA National Climate Data Center. Normalized anomalies shown in Fig. 2 are a composite of Kodiak, King Salmon and Cold Bay station records for November to March. We created an index of several widely dispersed reporting stations in order to reflect historical changes seen in the winter temperatures over the entire region covered in our study. An understanding of the degree of residual winter cooling is probably critical for the understanding of the population changes of near-shore species. GOA water temperatures at depth (GAK1; $250 \mathrm{~m}$ ) were obtained from the Institute of Marine Science, Univ. of Alaska, Fairbanks. These data span only 1971 to 1997 , and normal-

Fig. 1. Distribution of small-mesh trawl surveys $(n=8996)$ in the Gulf of Alaska between 1953 and 1997 
ized anomalies in Fig. 2 were calculated from data collected from May 15 to September 15 (fall/winter data were too infrequent to use for multi-year trends). This index reflects the deepest extent of the distribution of sampling undertaken in this study; only 66 tows were conducted in water deeper than $250 \mathrm{~m}$. This index is also useful for contrasting with SST data, which may or may not reflect heat content of the entire water column.

For illustrative purposes, annual CPUE, percent composition, and climate anomaly data were smoothed using 3 yr running averages. All statistics were calculated from unsmoothed data.

\section{RESULTS}

For the period of record (1953 to 1997), trawl catch biomass was dominated by 3 taxonomic groups (Fig. 2): shrimp (36\%), cod and pollock (33\%) and flatfish $(15 \%)$. Although 435 individual taxa were identified, 10 taxa comprised $90 \%$ of the total biomass (in order of abundance): northern shrimp Pandalus borealis, walleye pollock Theragra chalcogramma, flathead sole Hippoglossoides elassodon, Pacific cod Gadus macrocephalus, humpy shrimp $P$. goniurus, jellyfish Scyphozoa, arrowtooth flounder Atheresthes stomias, sidestripe shrimp Pandalopsis dispar, yellowfin sole Pleuronectes asper and capelin Mallotus villosus.

When the Aleutian Low was weak (negative NPPI), and coastal water temperatures were anomalously low, shrimp dominated in catches (Fig. 2). During periods with a strong Aleutian Low and warm coastal waters, the system was dominated by gadids and flatfish. The proportion of shrimp in catches was negatively correlated $(r=-0.47, p=0.003)$ with coastal SSTs. From 1971 to 1997, the proportion of shrimp in catches $(r=-0.72, p<0.0001)$ and absolute catches (CPUE, $r=-0.71, p<$ 0.0001 ) were strongly correlated with bottom $(250 \mathrm{~m})$ water temperatures, which explained $51 \%(\mathrm{p}=0.001)$ of the variation in shrimp CPUE. The proportion in catch of cod and pollock ( $\mathrm{r}=0.55, \mathrm{p}=0.003)$ and flatfish ( $\mathrm{r}=0.68$, $\mathrm{p}<0.0001$ ) were positively correlated with bottom temperatures, but absolute catches were not.

As indicated by abrupt changes in NPPI, air temperature and SST anomalies (Fig. 2), average climate in the GOA shifted from cool to warm around 1977 (Mantua et al. 1997). Standardized trawl data collected from 1972 to
1997 reveal the ecological impact of this climate regime shift (Fig. 3). We note a few obvious patterns. Whereas most of the increasing taxa are benthic or demersal in the adult stage (cod, pollock, flatfish, starfish), some are pelagic (jellyfish, cephalopods); and while most decreasing taxa are generally pelagic as adults, some are benthic (crabs). Most of the 'variable' taxa that exhibited little or no trend had 1 trait in common: they were all scarce.

Average total catch biomass declined by $55 \%$ from $348 \mathrm{~kg} \mathrm{~km}^{-1}$ in 1972 to 1981 to $159 \mathrm{~kg} \mathrm{~km}^{-1}$ in 1982 to 1990 (Fig. 4), due mostly to a marked reduction in catches of forage species. Average catches then increased by $265 \%$ to $422 \mathrm{~kg} \mathrm{~km}^{-1}$ during 1991 to 1997 due to an explosive increase in groundfish abundance. Overall, the abundance of predatory groundfish and forage species (including juvenile pollock $<20 \mathrm{~cm}$ ) were negatively correlated $(r=-0.47)$ and groundfish explained $23 \%(p=0.014)$ of the variance in catch of forage species.

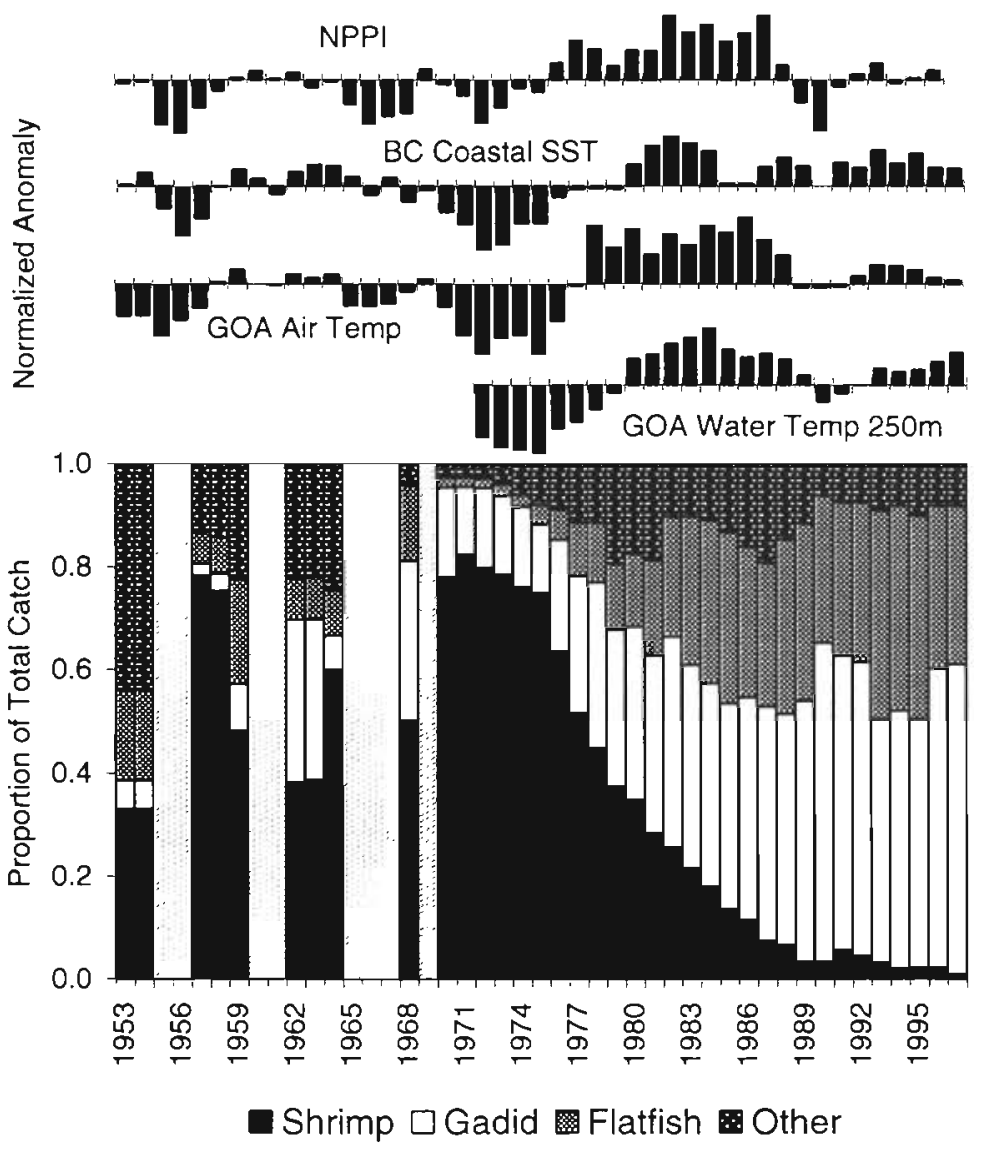

Fig. 2. Composition of small-mesh trawl catches in the Gulf of Alaska (GOA) between 1953 and 1997 in relation to climate indices. Climate data expressed as normalized anomalies. NPPI: North Pacific Pressure Index; BC: British Columbia; SST: sea surface temperature. Trends were smoothed by taking 3 yr running averages 


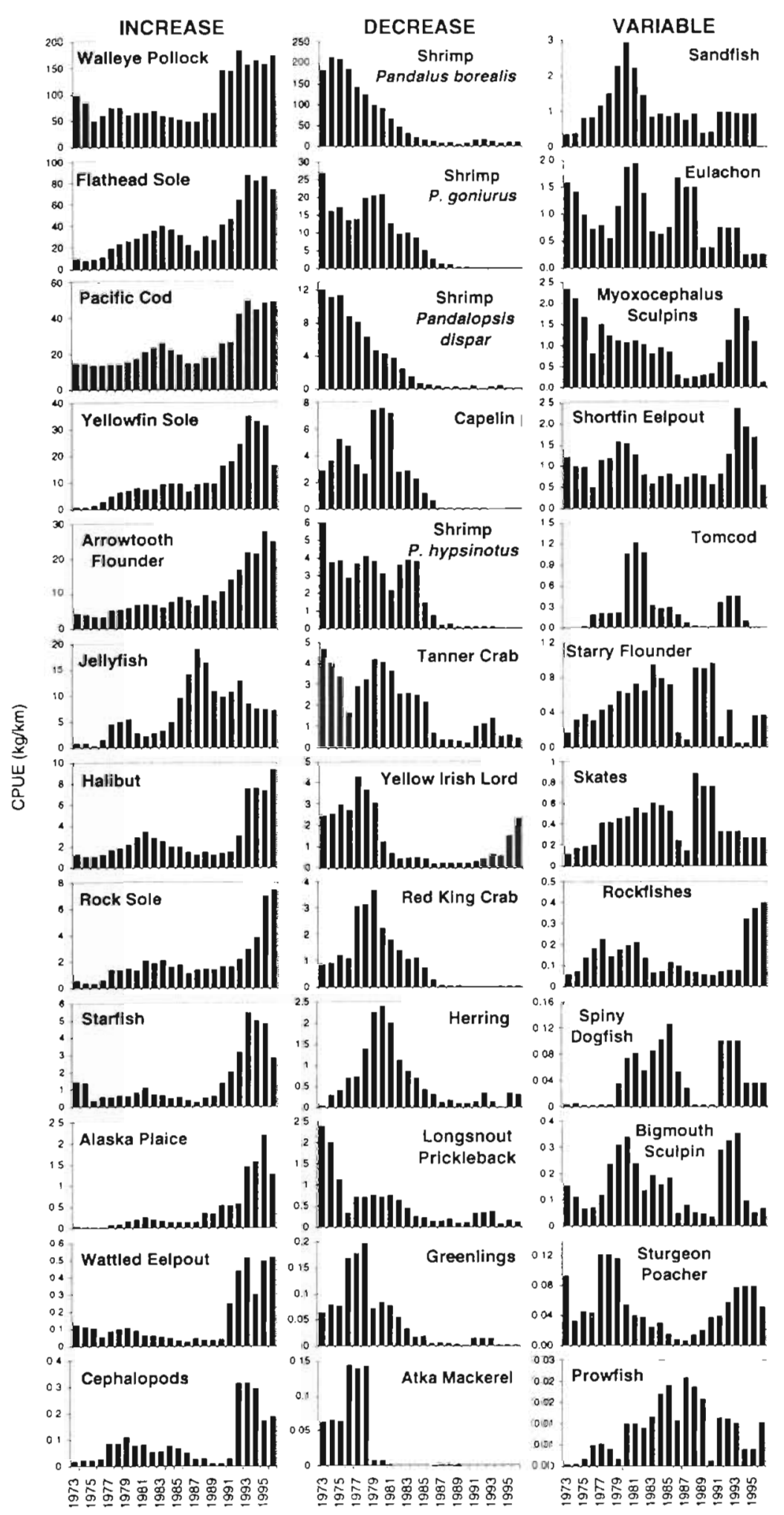

Fig. 3. Trends in catch biomass (CPUE) for 35 taxa caught in standardized. small-mesh trawls conducted between 1972 and 1997. Taxa are ranked from highest (top) to lowest (bottom) in abundance for each category (increasing, decreasing, variable). These taxa account for more than $98 \%$ of the total biomass caught in all years. Trends were smoothed by taking 3 yr running averages

\section{DISCUSSION}

These data provide compelling evidence of community reorganization following the 1977 climate regime shift for all the abundant taxa caught in shrimp stock assessment trawls. The transition from cold- to warm-regime community structure lagged temperature changes and required 15 to $20 \mathrm{yr}$ to complete in the GOA, although transition times of only 2 to $5 \mathrm{yr}$ were observed in individual bays (Anderson et al. 1997). The strength of association between shrimp catches and water temperature supports the hypothesis that the GOA ecosystem is regulated to a large degree by 'bottom-up' processes (Francis et al. 1998, McGowan et al. 1998)

Although there were historically large fisheries for pandalid shrimp in many areas (Orensanz et al. 1998), they also declined in areas that were seldom if ever fished (Anderson \& Gaffney 1977) and populations continued to decline even after fisheries were eliminated. Capelin have never been targeted by commercial fisheries in the GOA. Simultaneous declines were also noted in ecologically disparate taxa such as crabs, sculpins, herring, pricklebacks, eelpouts, snailfish, greenling, sablefish and Atka mackerel. Commercial fisheries may partially explain interannual fluctuations in abundance of some species (Orensanz et al. 1998), but the geographic and temporal coherence of the collapse of so many taxa argues for a large-scale common cause such as climate change-a conclusion also reached by Orensanz et al. (1998).

In contrast, the lag and relatively smooth increase in groundfish biomass are probably due to their biological characteristics: long life, delayed maturity, and intermittent strong recruitment. Under a long period of apparently favorable conditions, the bulk of total catch biomass accumulated in these species. The impact of commercial fishing on these trends is unclear. Pollock stocks were fished from 1972 to 1997 at a steady rate of 10 to $20 \%$ (Hollowed et al. in press) and so fishing may have had some effect on total abundance but probably little effect on trend. Similar patterns of increasing biomass and recruitment have been observed in flatfish species that were heavily fished (yellowfin sole, halibut) and those seldom 


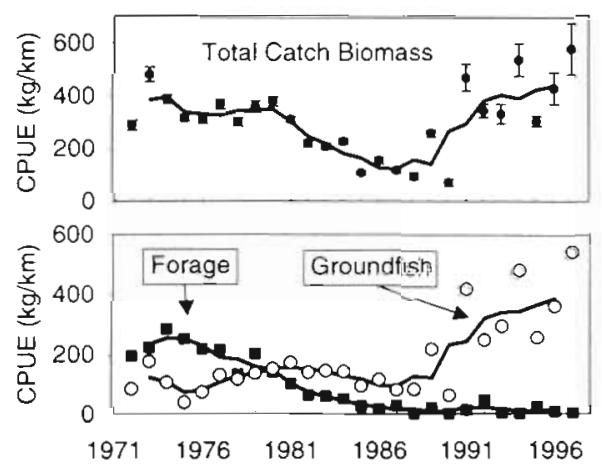

Fig. 4. Trends in catch biomass (CPUE) of combined taxa in standardized small-mesh trawls conducted between 1972 and 1997. Upper panel shows catch biomass ( \pm SE) of all taxa, and bottom panel shows separate trends for groundfish (cod, pollock, all flatfish) and forage species (all shrimps, capelin, smelts, sandfish, herring, juvenile pollock $<20 \mathrm{~cm}$ ). Lines show 3 yr running averages

fished (arrowtooth flounder). Increases were also noted in ecologically disparate taxa, including starfish, jellyfish, eelpout and cephalopods. Again, the coherence in population trends of these taxa, fished or not, argue for a common cause such as climate change.

The mechanism by which the physical regime shift may have caused such a broad ecological regime shift is unknown (Francis et al. 1998, McGowan et al. 1998). For Pacific salmon, a working hypothesis is that increased wind forcing in the GOA promoted an increase in phyto- and zooplankton production which in turn enhanced salmon recruitment after 1977 (Brodeur \& Ware 1992, Francis \& Hare 1994, Mantua et al. 1997). However, this hypothesis does not explain why numerous other taxa declined. The 'match-mismatch' hypothesis, which suggests that recruitment depends strongly on a temporal match in timing of larval emergence and availability of zooplankton prey (Cushing 1995), may better explain differences in population trends among taxa. The chronology in peak development of Neocalanus copepod biomass in the Alaska Gyre changed markedly over the past $40 \mathrm{yr}$ (Mackas et al. 1998). Seasonal biomass peaks were 1 to 2 mo later during the cold regime than the warm regime. Surface $(0$ to $150 \mathrm{~m})$ water temperatures explained $>50 \%$ of the variance in chronology. In warm years the peak biomass period was characteristically earlier, of shorter duration, and resulted in higher biomass concentrations (Mackas et al. 1998).

Variability in the timing of zooplankton production could have a profound effect on recruitment of fish and decapods in the GOA. The majority of shrimp and crabs in the GOA release larvae in spring or early summer (Orensanz et al. 1998). Two of the strongest year classes of shrimp ever recorded were the 1971 and 1975 year classes (Anderson 1991), corresponding to the latest years of peak zooplankton biomass development in the Alaska Gyre (Mackas et al. 1998). Similarly, red king, brown king, and Tanner crabs Chionoecetes bairdi all exhibited recruitment peaks in the early 1970s (Orensanz 1998). Capelin are late spring and early summer spawners, and their larvae are among the last to enter the water column in the GOA (NMFS unpubl. data). We therefore expect that capelin would be negatively affected by a shift towards earlier zooplankton biomass peaks.

In contrast, the shift towards earlier zooplankton availability might favor early-spawning fishes such as pollock and several flatfish species. Pollock spawn in February to March and larvae reach peak abundance in late April to early May in the northwestern GOA. Survival is thought to be strongly dependent on food availability at that time (Bailey et al. 1995). There were far more strong recruitment years between 1977 and 1997 than between 1964 and 1976 (Hollowed \& Wooster 1992). Pacific halibut Hippoglossus stenolepis spawn from November to March near the continental shelf-edge, and larvae reside in surface waters for about 6 mo before settling to the bottom. Recent models (Clark et al. 1999) suggest that halibut recruitment increased sharply in the early 1980s, reaching a plateau through the 1990 s that was nearly double that observed during the cooler period from 1947 to 1977.

A corollary hypothesis is that predation amplified declines of forage species. Cod, pollock, arrowtooth flounder, and halibut all prey on shrimp, capelin and other forage species (Albers \& Anderson 1985, Livingston 1993, Yang 1993), and may have accelerated their decline. It is noteworthy that in several bays in the GOA, shrimp and capelin populations collapsed rapidly as groundfish increased inshore (Albers \& Anderson 1985, Anderson et al. 1997). The negative correlation observed here between predator and prey taxa and diet trends of groundfish reported elsewhere support the hypothesis that the GOA ecosystem is also regulated to some degree by 'top-down' processes (Francis et al. 1998, McGowan et al. 1998).

Decadal fluctuations in biomass and composition of fish communities apparently had a direct impact on sea birds and marine mammals that subsist on forage species and juvenile age groups of groundfish (Francis et al. 1998). During the cold regime prior to 1977, seabirds and marine mammals relied on fatty forage species such as capelin. As forage biomass declined in the early 1980s, fatty forage species disappeared from bird and mammal diets and were replaced largely by juvenile pollock (Piatt \& Anderson 1996, Merrick et al. 1997). Declines in production and abundance of several sea bird and marine mammal populations in the GOA followed (Piatt \& Anderson 1996). Because juvenile pollock have low energy densities compared to 
fatty forage species such as capelin (Van Pelt et al. 1997), some predator declines may be attributable to changes in diet composition. Perhaps more importantly, the total biomass of all forage taxa, including juvenile pollock, may now be limiting, owing to the enormous food demands of adult groundfish - which now outweigh those of sea birds and marine mammals (and human fisheries) by 1 to 2 orders of magnitude (Livingston 1993, Yang 1993, Hollowed et al. in press).

We note some parallels with events in the North Atlantic, where shrimp Pandalus spp., capelin Mallotus villosus and cod Gadus morhua are dominant members of that marine ecosystem. A widespread 'gadoid outburst' of the 1960 s was associated with warming temperatures and a shift in the timing and composition of zooplankton biomass (Cushing 1995). The more recent collapse of northwest Atlantic cod fisheries in the 1980s has been attributed to overfishing but also to recruitment and production failure associated with ocean climate change (deYoung \& Rose 1993). In contrast, as groundfish stocks collapsed, the commercial catches of pandalid shrimp, capelin and crabs increased dramatically in the Northwest Atlantic (Frank et al. 1996, Hvingel \& Savard 1997, Pederson 1998, P. A. Koeller \& K. Drinkwater, Bedford Inst. Oceanogr., Dartmouth, NS, Canada, pers. comm.). We recognize that the situation in the Atlantic is complicated by long-term human influences and we are not suggesting that changes observed there are only a result of climate change. In any case, it does appear that forage species such as pandalid shrimp and capelin may be leading indicators of decadal-scale changes in northern marine ecosystems because of their short life spans and low trophic levels.

As in the Atlantic (Aebischer et al. 1990), we found tantalizing evidence that long-term changes at multiple trophic levels in the GOA are associated with large-scale changes in marine climate. However, biological changes in both oceans have been correlated with changes in marine climate over only part of a climate cycle, and cause-and-effect relationships are not established by these observations. We need to observe changes over a complete climate cycle (e.g. cold to warm to cold regime), and preferably several cycles, before drawing strong conclusions about biological effects of climate change. In the interim, we can make some basic predictions to test the hypothesis. Ware (1995) has analyzed climatological data from the NE Pacific and found statistically significant decadalperiod cycles in the temperature time-series of the past century. He concluded that the recent warm regime should end soon, and that the GOA should return to cold regime conditions in the early 2000 s. If this proves true, then we predict that catches of indicator species such as shrimp and capelin will soon increase in shrimp assessment trawls, and that the diets of seabirds and marine mammals will reflect the increased availability of forage species over the next few years. Similarly, we would predict imminent (but slower) declining trends in catches of groundfish and salmon in the Gulf of Alaska.

Acknowledgements. We wish to acknowledge grants from the Exxon Valdez Oil Spill Trustee Council (APEX Project 98163L) in support of analysis of the GOA trawl data. We thank J. E. Blackburn and W. Bechtol (ADF\&G) for their invaluable input. Data and discussion on climate indices were kindly provided by S. Hare, N. Mantua, and T. Royer, and we are grateful to A. Hollowed, P. Livingston, S. Hare, D. Mackas and $W$. Clark for access to unpublished data and manuscripts. We thank J. Blackburn, R. Brodeur, R. Francis, S. Hare, A Hollowed, A. Kitaysky, P. Livingston, D. Mackas, C. Peterson, G. van Vliet and W. Wooster for constructive reviews of the paper.

\section{LITERATURE CITED}

Aebischer NJ, Coulson JC, Colebrook JM (1990) Parallel long-term trends across four marine trophic levels and weather. Nature 347:753-755

Albers WD, Anderson PJ (1985) Diet of the Pacific cod, Gadus macrocephalus, and predation on the northern pink shrimp, Pandalus borealis, in Pavlof Bay, Alaska. Fish Bull US 83:601-610

Anderson PJ (1991) Age, growth, and mortality of the northern shrimp Pandalus borealis Kröyer in Pavlof Bay, Alaska. Fish Bull US 89:541-553

Anderson PJ, Gaffney FG (1977) Shrimp of the Gulf of Alaska. Alask Seas Coasts 5(3):1-3. Available from University of Alaska, Alaska Sea Grant College Program, Fairbanks

Anderson PJ, Blackburn JE, Johnson BA (1997) Declines of forage species in the Gulf of Alaska, 1972-95, as indicator of regime shift. In: Baxter $B S$ (ed) Proceedings of the International Symposium on the Role of Forage Fishes in Marine Ecosystems November 13-16, 1996, Anchorage, Alaska. University of Alaska Sea Grant Rep 97-01, p 531-543

Bailey KM, Canino M, Napp J, Spring S, Brown A (1995) Contrasting years of prey levels, feeding conditions and mortality of larval walleye pollock Theragra chalcogramma in the western Gulf of Alaska. Mar Ecol Prog Ser 119:11-23

Bechtol WR (1997) Changes in forage fish populations in Kachemak Bay, Alaska, 1976-1995. In: Baxter BS (ed) Proceedings of the International Symposium on the Role of Forage Fishes in Marine Ecosystems November 13-16. 1996. Anchorage, Alaska. University of Alaska Sea Grant Rep 97-01, p 441-455

Botsford LW, Castilla JC, Peterson CH (1997) The management of fisheries and marine ecosystems. Science 277 : 509-515

Brodeur RD, Ware DM (1992) Long-term variability in zooplankton bjomass in the subarctic Pacific Ocean. Fish Oceanogr 1:32-38

Clark WG, Hare SR, Parma AM, Sullivan PJ, Trumble RJ (1999) Decadal changes in growth and recruitment of Pacific halibut (Hippoglossus stenolepis). Can J Fish Aquat Sci 56: 242-252

Cushing D (1995) Population production and regulation in the 
sea: a fisheries perspective. Cambridge University Press, Cambridge

deYoung B, Rose GA (1993) On recruitment and distribution of Atlantic cod (Gadus morhua) off Newfoundland. Can J Fish Aquat Sci 50:2729-2741

Francis RC. Hare SR (1994) Decadal-scale regime shifts in the large marine ecosystems of the Northeast Pacific: a case for historical science. Fish Oceanogr 3:279-291

Francis RC, Hare SR, Hollowed AB, Wooster WS (1998) Effects of interdecadal climate variability on the oceanic ecosystems of the NE Pacific. Fish Oceanogr 7:1-21

Frank KT, Carscadden JE, Simon JE (1996) Recent excursions of capelin (Mallotus villosus) to the Scotian Shelf and Flemish Cap during anomalous hydrographic conditions. Can J Fish Aquat Sci 53:1473-1486

Hollowed AB, Wooster WW (1992) Variability of winter ocean conditions and strong year classes of northeast Pacific groundfish. ICES Mar Sci Symp 195:433-444

Hollowed AB, lanelli JN, Livingston P (in press) Including predation mortality in stock assessments; a case study for Gulf of Alaska walleye pollock. ICES Mar Sci Symp

Hvingel C, Savard L (1997) Northern shrimp research in the North Atlantic - state of the art and future research strategy. TemaNord 1997:592

Livingston PA (1993) The importance of predation by groundfish, marine mammals and birds on walleye pollock Theragra chalcogramma and Pacific herring Clupea pallasi in the eastern Bering Sea. Mar Ecol Prog Ser 102:205-215

Mackas DL, Goldblatt R, Lewis AG (1998) Interdecadal variation in developmental timing of Neocalanus plumchrus populations at Ocean Station $\mathrm{P}$ in the subarctic North Pacific. Can J Fish Aquat Sci 55 1878-1893

Mantua NJ, Hare SR, Zhang Y, Wallace JM, Francis RC (1997) A Pacific interdecadal climate oscillation with impacts on salmon production. Bull Am Meteorol Soc 78: 1069-1079

McGowan JA, Cayan DR, Dorman LM (1998) Climate-ocean variability and ecosystem repsonse in the Northeast Pacific. Science 281:210-217

Merrick RL, Chumbley K, Byrd GV (1997) Diet diversity of

Editorial responsibility: Charles Peterson (Contributing

Editor), Morehead City, North Carolina, USA
Steller sea lions (Eumetopias jubatus) and their population decline in Alaska: a potential relationship. Can J Fish Aquat Sci 54:1342-1348

Orensanz JM, Armstrong J, Armstrong D, Hilborn R (1998) Crustacean resources are vulnerable to serial depletion the multifaceted decline of crab and shrimp fisheries in the greater Gulf of Alaska. Rev Fish Biol Fish 8:117-176

Pedersen SA (1998) Distribution and lipid composition of Pandalus shrimp larvae in relation to hydrography in west Greenland waters. J Northwest Atl Fish Sci 24:39-60

Piatt JF, Anderson PJ (1996) Response of common murres to the Exxon Valdez oil spill and long-term changes in the Gulf of Alaska marine ecosystem. In: Rice SD, Spies RB, DA Wolfe, Wright BA (eds) Exxon Valdez oil spill symposium proceedings. American Fisheries Society Symposium 18, Bethesda, MD, p 720-737

Polovina JJ, Mitchum GT, Evans CT (1995) Decadal and basin-scale variation in mixed layer depth and the impact. on biological production in the central and North Pacific, 1960-88. Deep-Sea Res 42:1701-1716

Ronholt LL (1963) Distribution and relative abundance of commercially important pandalid shrimps in the northeastern Pacific Ocean. US Fish Wildl Serv Spec Sci Rep Fish 449

Steele JH (1991) Marine functional diversity. BioScience 41:179-194

Van Pelt T, Piatt JF, Lance BK, Roby DD (1997) Proximate composition and energy density of some North Pacific forage fishes. Comp Biochem Physiol 118(A):1393-1398

Ware DM (1995) A century and a half of change in the climate of the NE Pacific. Fish Oceanogr 4:267-277

Wilson JG, Overland JE (1986) Meteorology. In: Hood DW, Zimmerman ST (eds) The Gulf of Alaska: physical environment and biological resources. US Departments of Commerce and the Interior, Minerals Management Service Publ OCS Study MMS86-0095, Anchorage, Alaska, p 31-54

Yang M (1993) Food habits of the commercially important groundfishes in the Gulf of Alaska in 1990. US Dept of Commerce, NOAA Tech Memoran MMFS-AFSC-22

Submitted: January 26, 1999; Accepted: June 8, 1999

Proofs received from author(s): November 15, 1999 